sum against the light of the sky as a background might aftord it a protection from enemies below; and the dark of the venter against the dark background of the earth, a protection from those above it.

Many such cases can be regarded more clearly as protective since we now know that insects probably do not see form, but color and movement.

\title{
DESCRIPTION OF EGGS AND LARVA OF APATELODES TORREFACTA.
}

\author{
By CAROLINE G. SOULE, BROOKLINE, Mass.
}

A female found at Nonquitt, Mass., on I3 July i 888 , laid a mass of pale green eggs, circular, flat on both top and bottom, translucent, and looking like tiny gelatine lozenges, $1.5 \mathrm{~mm}$. in diameter. 2o July, the embryo could be seen - with a lens. Five days later the eggs had become opaque and of a sordid yellowish white color. $26 \mathrm{July}$, the young larvae hatched, being a trifle less than $6 \mathrm{~mm}$. long, covered with long white hairs, and having a few dark ones near the head and the anal shield.

The head, body, feet, and props were pale yellow, without marks.

The hair was dense, long over the anal end, shorter over the middle, and still longer on first three segments. The body became green with food. The larvae rested on both sides of the sassafras (Sassafras officinale) and ash (Fraxinus) leaves, and moved very fast. A slight jar sufficed to make them fall from the leaf and drop by a silken thread.

When touched they curled up like the arctians. They drank greedily, and ate their cast skins.
Those Miss Ida M. Eliot had ate beach-plum (Prunus maritima) and oak (2uercus).

Some sent to Miss Emily M. Norton ate wild-cherry (Prunus).

2 Aug. The larvae molted, becoming even whiter and "fluffier" than before, with a dorsal line of black dashes, and a dark pencil on the tenth segment. A few had gray hairs over the head.

5 Aug. They molted for the second time;--as before with the addition of a gray pencil on the second and third segments.

Feet and props were conspicuously white.

Io Aug. Third molt. $25 \mathrm{~mm}$. long, body green ; feet and props white; head sordid white; hair very long and silky, and from each dorsal dash sprung a short black pencil.

A lateral and subventral line of black arrow-heads appeared.

One larva became bright yellow with the pencils tan-colored with black tips, and one was of a soft gray with black pencils. 
I 5 Aug. Fourth molt.

The venter was black, and the props were black with white tips. On first and second segments, the arrow-heads were replaced by vertical black dashes, extending nearly to the dorsal line.

The yellow one came out with the body black, the hair Maltese-gray, lighter over the head; pencils darker gray with black tips. The gray one was like it.

26 Aug. Adult larva, 5 I mm. long, densely covered with long silky hairvarying in color from pure white to deep gray. Pencils almost black with black tips. Head gray.

Body hardly to be seen but black wherever visible. Props black with red tips. Feet black.

27 Aug. Three shed all their pencils and long hair, emptied themselves, and crawled rapidly about as if hunting for good places to pupate. Rotten wood and bark were provided, but no attention was paid to them, and no signs of spinning were found.

3o Aug. The pupae appeared, bright apple green, with three abdominal rows of gray dots, at first, but they soon became of a uniform mahogany color, very shining and bright, about $19 \mathrm{~mm}$. long.

Some were in close tins, and some in a paste-board box, but those in tin pupated first.

The larvae fed on sassafras grew faster and larger than those fed on ash, and molted and pupated earlier.

As the larvae grew older they chose older leaves, in preference to young and tender ones, as food.

This I have noticed with all my larvae this year.

\section{ELECTRIC LIGHT CAPTURES.}

BY JOHN HAMILTON, ALLEGHENY, PA.

The reputed rarity of an insect is frequently owing to its ability to conceal itself and a want of knowledge in the collector regarding its habits, whereas it may be really abundant. This is exemplified in the instances of Calosoma scrutator and $C$. willcoxi. During near twenty years of collecting here I only took a single living specimen of each; Mr. Klages who has collected near half that time - and carefully, was not more successful, nor were several amateurs whose collections were seen.
Yet all this time there were thousands of these insects about us as we now know. This year (r888) the evenings of 9 , ro and I I May were warm, temperature $60^{\circ}$ to $65^{\circ} \mathrm{F}$. During one hour of each of these evenings I picked up from the platform of an open pavilion in one of our parks in the centre of the city, to the corners of which powerful electric lights were suspended, ninety $q$ and thirty $\delta$ Calosoma scrutator; one hundred and ten $q$ and twenty-six $\delta$ C. willcoxi. Three weeks of low tem- 

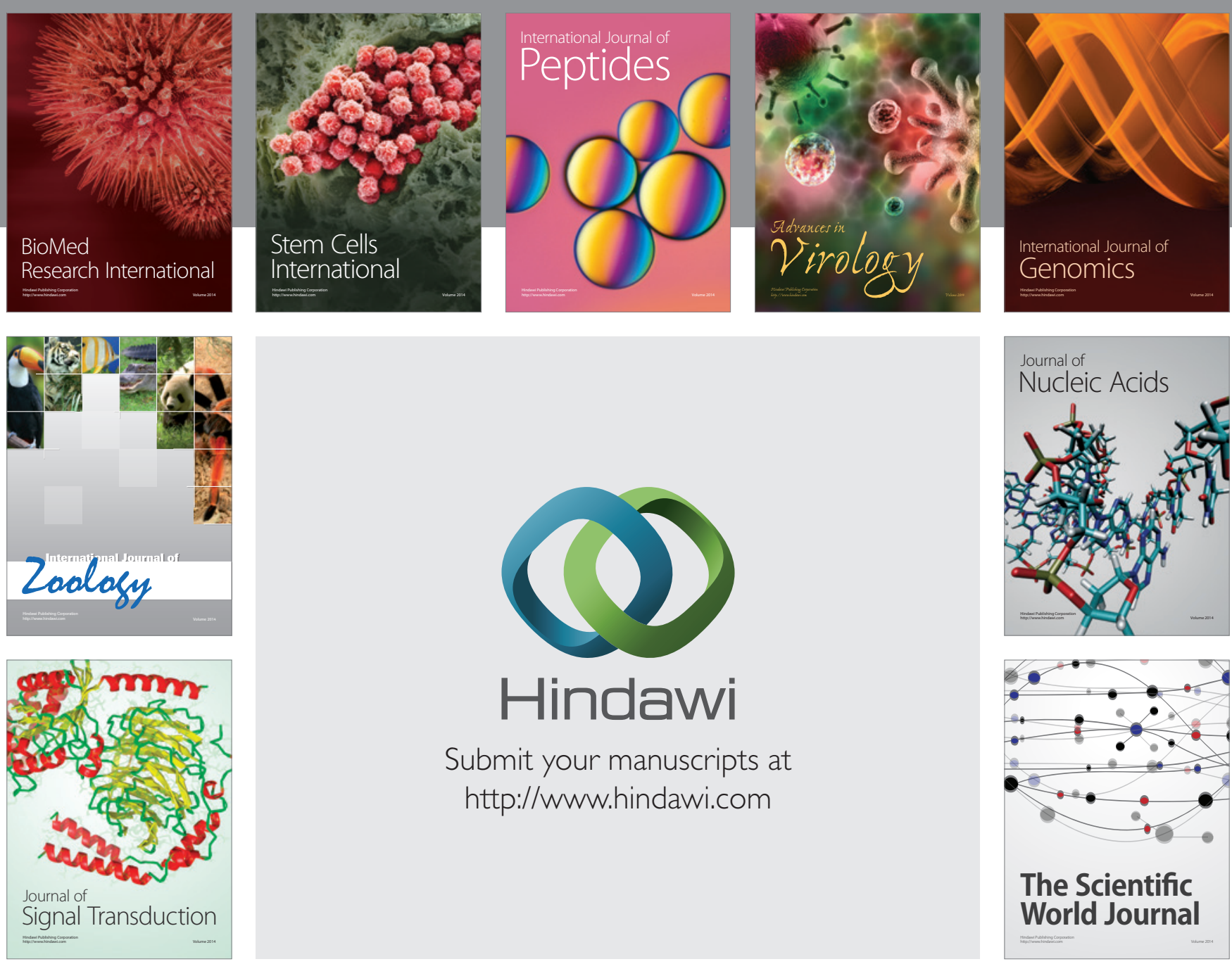

Submit your manuscripts at

http://www.hindawi.com
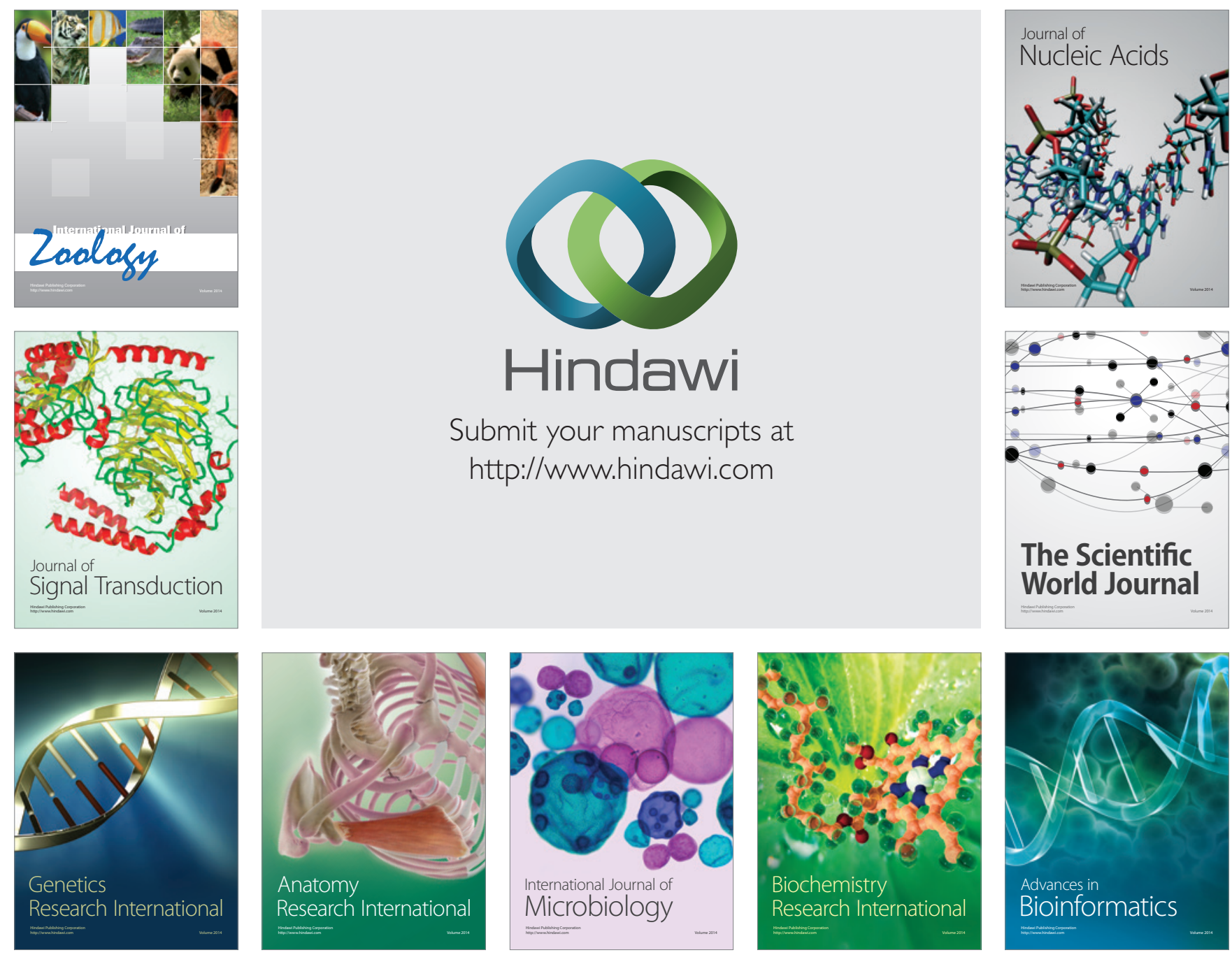

The Scientific World Journal
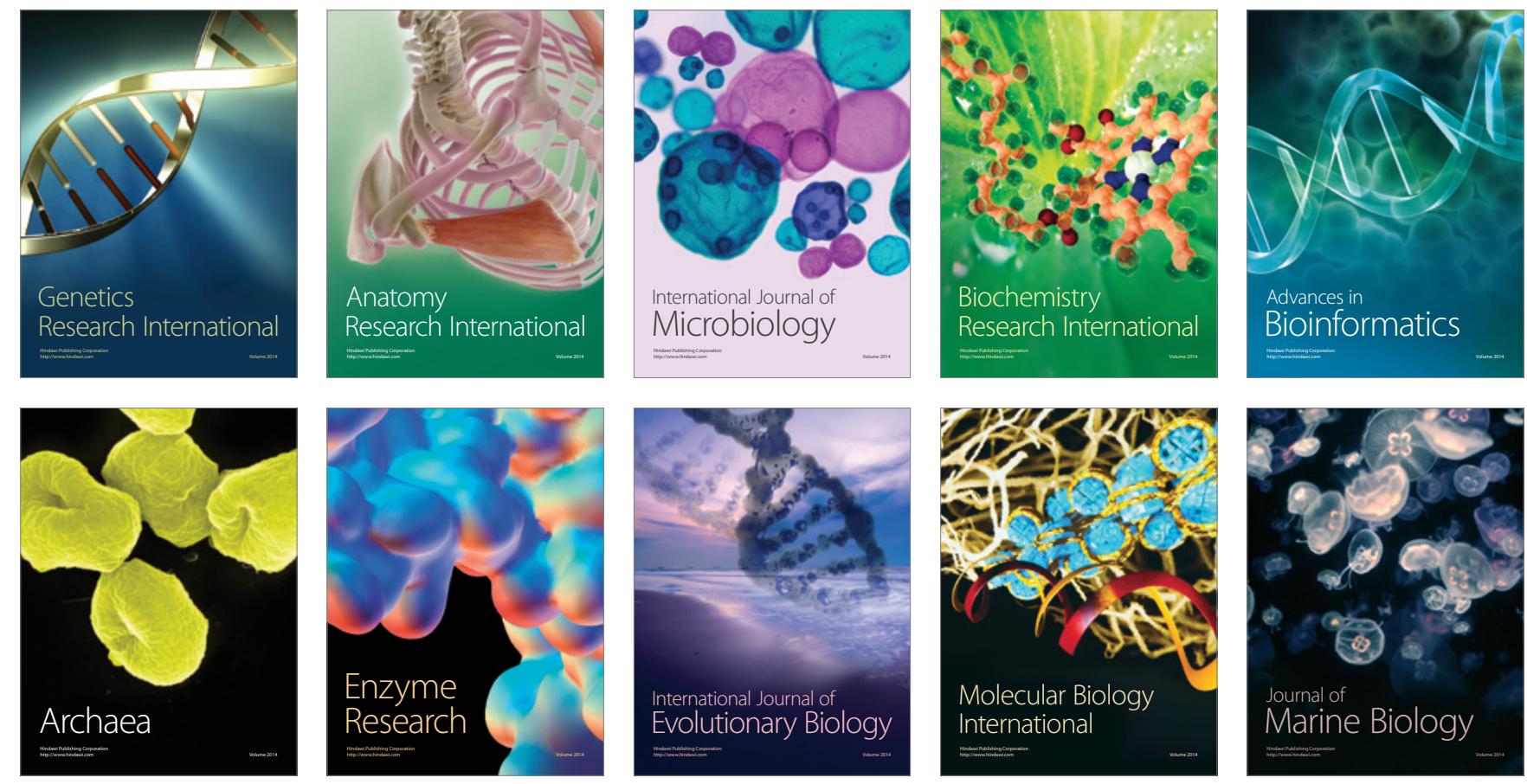